May 2007

\title{
Sentinel node staging for breast cancer: Intraoperative molecular pathology overcomes conventional histologic sampling errors
}

\author{
Peter Blumencranz \\ Morton Plant Mease Health Care, Clearwater, FL \\ Pat W. Whitworth \\ Nashville Breast Center, Nashville, TN \\ Kenneth Deck \\ South Orange County Surgical Medical Group, Laguna Hills, CA \\ Anne Rosenberg \\ Thomas Jefferson University \\ Follow this and additional works at: https://jdc.jefferson.edu/surgeryfp \\ T-uglas Reintgen \\ Lakepand Regionapeancercenter, Lakeland, FL \\ Let us know how access to this document benefits you
}

\section{See next page for additional authors}

\section{Recommended Citation}

Blumencranz, Peter; Whitworth, Pat W.; Deck, Kenneth; Rosenberg, Anne; Reintgen, Douglas;

Beitsch, Peter; Chagpar, Anees; Julian, Thomas; Saha, Sukamal; Mamounas, Eleftherios;

Giuliano, Armando; and Simmons, Rache, "Sentinel node staging for breast cancer:

Intraoperative molecular pathology overcomes conventional histologic sampling errors" (2007).

Department of Surgery Faculty Papers. Paper 5.

https://jdc.jefferson.edu/surgeryfp/5

This Article is brought to you for free and open access by the Jefferson Digital Commons. The Jefferson Digital Commons is a service of Thomas Jefferson University's Center for Teaching and Learning (CTL). The Commons is a showcase for Jefferson books and journals, peer-reviewed scholarly publications, unique historical collections from the University archives, and teaching tools. The Jefferson Digital Commons allows researchers and interested readers anywhere in the world to learn about and keep up to date with Jefferson scholarship. This article has been accepted for inclusion in Department of Surgery Faculty Papers by an authorized administrator of the Jefferson Digital Commons. For more information, please contact: JeffersonDigitalCommons@jefferson.edu. 


\section{Authors}

Peter Blumencranz, Pat W. Whitworth, Kenneth Deck, Anne Rosenberg, Douglas Reintgen, Peter Beitsch, Anees Chagpar, Thomas Julian, Sukamal Saha, Eleftherios Mamounas, Armando Giuliano, and Rache Simmons 


\section{Sentinel node staging for breast cancer: intraoperative molecular pathology overcomes conventional histologic sampling errors}

Presented at the 8th Annual Meeting of the American Society of Breast Surgeons, Phoenix, AZ, May 2-6, 2007

Peter Blumencranz M.D. ${ }^{a}$, Pat W. Whitworth M.D. ${ }^{b, *}$, Kenneth Deck M.D. ${ }^{c}$, Anne Rosenberg M.D. ${ }^{d}$, Douglas Reintgen M.D. ${ }^{e}$, Peter Beitsch M.D. ${ }^{f}$, Anees Chagpar M.D. ${ }^{g}$, Thomas Julian M.D. ${ }^{\text {h }}$, Sukamal Saha M.D. ${ }^{i}$, Eleftherios Mamounas M.D.', Armando Giuliano M.D. ${ }^{\mathrm{k}}$ and Rache Simmons M.D.'

${ }^{a}$ Breast Health Services, Morton Plant Mease Health Care, 303 Pinellas St, Ste. 310, Clearwater, FL 33756, USA

${ }^{\mathrm{b}}$ Nashville Breast Cancer, 300 20th Avenue North, Suite \#401, Nashville, TN 37205, USA

'South Orange County Surgical Medical Group, 24411 Health Center Dr, Ste. 350, Laguna Hills, CA 92653, USA

${ }^{d}$ Thomas Jefferson University Hospital, 132 S. 10th St, Philadelphia, PA 19107, USA

' Lakeland Regional Cancer Center, 3525 Lakeland Hills Blvd, Lakeland, FL 33805, USA

'Dallas Surgical Group, 5920 Forest Park Rd, Ste. 500, Dallas, TX 75235, USA

gJames Brown Cancer Center, Department of Surgery, Div. of Surgical Oncology (Box M10), 315

E. Broadway, Ste. 312, Louisville, KY 40202, USA

${ }^{\mathrm{h}}$ Alleghany Cancer Center, WestPenn Allegheny Health System, 320 E. North Ave, Pittsburgh, PA 15212, USA

'McLaren Regional Medical Center, Department of Surgery, 3500 Calkins Rd, Ste. A, Flint, MI 48532, USA

jAultman Hospital, Clinical Trials Department, 2600 6th St, S.W., Canton, OH 44710, USA

kJohn Wayne Cancer Institute, 2200 Santa Monica Blvd, Ste. 113, Santa Monica, CA 90404, USA

'Weill-Cornell Breast Center, 425 E. 61st St, 8th Floor, New York, NY 10021, USA

${ }^{*}$ Corresponding author. Tel.: 615-284-8229; fax: 615-284-2026.

\section{Abstract}

\section{Background}

When sentinel node dissection reveals breast cancer metastasis, completion axillary lymph node dissection is ideally performed during the same operation. Intraoperative histologic techniques have low and variable sensitivity. A new intraoperative molecular assay (GeneSearch BLN Assay; Veridex, LLC, Warren, $\mathrm{NJ}$ ) was evaluated to determine its efficiency in identifying significant sentinel lymph node metastases (>.2 mm).

\section{Methods}

Positive or negative BLN Assay results generated from fresh 2-mm node slabs were compared with results from conventional histologic evaluation of adjacent fixed tissue slabs. 


\section{Results}

In a prospective study of 416 patients at 11 clinical sites, the assay detected $98 \%$ of metastases $>2 \mathrm{~mm}$ and $88 \%$ of metastasis greater $>.2 \mathrm{~mm}$, results superior to frozen section. Micrometastases were less frequently detected $(57 \%)$ and assay positive results in nodes found negative by histology were rare $(4 \%)$.

\section{Conclusions}

The BLN Assay is properly calibrated for use as a stand alone intraoperative molecular test.

\section{Keywords}

Breast cancer, Molecular, Gene, Diagnostic, Auxiliary

For breast cancer patients, the status of the axillary sentinel lymph node(s) (SLN) provides important staging information and usually determines whether formal axillary lymph node dissection will be performed. If axillary node dissection is needed, it is ideally performed immediately after SLN dissection during the same operation. Current, widely practiced, intraoperative methods for detecting SLN metastases include frozen section and touch preparation (imprint cytology). Both of these approaches have limited sensitivity with wide performance variability compared with postoperative permanent section histology. When compared with final permanent pathology results, the reported sensitivity of frozen section SLN analysis varies from $58 \%$ to $87 \%$ [1]. Touch preparation has similar limitations in sensitivity [2]. A positive intraoperative SLN finding spares the patient a later return to surgery for completion axillary dissection. However, substantial falsenegative findings with current histologic intraoperative methods cause patients and their families significant distress when they are told later that the test was incorrect. Not only must the patient and her family go through a second operation, but they also have to cope with the news that the prognosis is worse and the required treatment more extensive than they had believed. In addition, the second surgery after a false-negative frozen section incurs additional costs and potential additional anesthetic and operative morbidity.

Accurate intraoperative molecular analysis of all or part of the SLN offers the potential to significantly reduce false-negative findings that necessarily occur with the limited tissue sampling of conventional histologic methods [3], [4], [5], [6] and [7]. Although a molecular assay can overcome the errors resulting from limited tissue sampling associated with traditional histologic evaluation, several new challenges arise. First, unless calibrated appropriately, molecular assays may detect clinically insignificant amounts of metastatic cellular material. Presently, nodal breast cancer metastatic deposits $<.2 \mathrm{~mm}$ are classified as node negative 
$(\mathrm{N}-0)$ [8], with minimal or unknown clinical importance. A molecular breast SLN assay must be calibrated to routinely indicate a positive result only with quantities of disease $\geq .2 \mathrm{~mm}$ to spare patients from axillary dissections or adjuvant chemotherapy, which would be considered unwarranted by current standards. Second, the molecular assay must be validated in an independent dataset to confirm proper calibration.

The validation of a molecular SLN assay with accuracy superior to conventional sampling-based histology presents an even more challenging problem. Because of the likelihood that an accurate molecular assay will be more thorough than conventional histology, the assay will likely detect disease missed by the reference histologic test to which it is compared. Traditional test validation methodology would misleadingly term such a finding "false-positive." Therefore, a modified approach is needed.

We evaluated a novel, intraoperative reverse transcriptase-polymerase chain reaction assay for SLN breast cancer metastasis (GeneSearch BLN Assay; Veridex, LLC, Warren, NJ) in a prospective, multisite trial. The molecular test was calibrated in vitro so that positive findings were only associated with significant levels of the targeted messenger RNA transcripts [9]. We have presented a comprehensive, classic sensitivity and specificity evaluation of this new test elsewhere [10]. In the current analysis, we hypothesized that agreement between the molecular test on one part of the SLN and conventional pathology from another part (alternating slices) would be greatest when metastatic involvement was most extensive, as would be expected with histologic evaluation of alternating tissue sections of the same node. We also examined assay performance related to breast tumor type and stage and compared assay performance with the performance of current intraoperative tests. In particular, we investigated if the assay could be particularly beneficial for difficult-to-detect metastases, such as those seen in stage I cancer or lobular cancer. Lobular metastases are particularly challenging for conventional, sampling-based histologic methods because they are often distributed as diminutive clusters or single cells. There is growing consensus that such metastatic deposits should be counted as node positive, even when none is $>.2 \mathrm{~mm}$, when a substantial amount of the node is so involved [11].

\section{Methods}

The calibration and validation of the molecular BLN Assay required 2 separate trials: (1) a beta (cutoff) trial of 304 patients to establish a threshold between insignificant and significant levels (corresponding with histologic metastatic deposits $>.2 \mathrm{~mm}$ ) of the markers mammaglobin and cytokeratin 19 (CK19) and (2) a pivotal (validation) trial of 416 patients for independent performance verification compared with permanent-section hematoxylin and eosin and immunohistochemical evaluation. Both trials were completed between July 2004 and December 2005 (Pre-IDE I040002). Patients at least 18 years of age with a

Authors' version prior to publication. The published version is available at http://dx.doi.org/10.1016/j.amjsurg.2007.07.008, copyright @ 2007 by Excerpta Medica Inc. 
diagnosis of invasive adenocarcinoma of the breast and scheduled for a SLN dissection were eligible for the calibration or validation study. Patients were excluded if they were participating in other research studies that would prevent their full study participation, if they had a prior axillary surgery on the same body side as the scheduled SLN dissection, if proper informed consent signature was not obtained, or if they did not meet inclusion criteria listed earlier. All patients in the final data analysis had written informed consent, and the study protocols were reviewed and approved by the appropriate ethics review board at each site.

Twelve clinical sites in the United States were selected based on clinical trial performance history and previous research experience with SLN studies through the American College of Surgeon's Oncology Group or The National Surgical Adjuvant Bowel and Breast Project. Site technicians were trained and qualified with the BLN Assay technology.

\section{Node processing and comparison of BLN Assay findings with conventional histology}

SLNs were identified intraoperatively and dissected according to the standard procedures of each site. Nodes were transported to the pathology testing area within 15 minutes. All nodes designated as sentinel nodes (including "grossly positive" nodes) were analyzed, except at the site pathologist's discretion (ie, node too small for adequate histological assessment for patient care if shared for molecular assay) or because of protocol deviation. Each node was sectioned along the short axis into an even number of slabs (1.5-3.0 mm thick). Alternate slabs were prepared for histologic evaluation or the BLN Assay. Histologic evaluation of each lymph node complied with or exceeded current College of American Pathologists' recommendations. The BLN Assay procedure using reverse-transcriptase polymerase chain reaction includes liquefaction of the selected tissue, allowing comprehensive analysis of all cellular material in the tissue sample, thus eliminating sampling error. Unfortunately, the same tissue slab cannot be examined by both the BLN assay, which uses fresh tissue, and conventional histology, which uses formalin-fixed tissue. This makes direct comparison between the 2 methods on the exact same tissue impossible. Comparison of findings from adjacent tissue slabs is required. Perfect concordance between adjacent tissues cannot be expected because small metastases may be singular or spaced several millimeters apart. However, if both tests accurately detect metastatic disease, increasing the number or size of the metastatic cellular colonies will be associated with an increasing concordance of findings in adjacent tissue slabs.

\section{Site slides and histologic intraoperative tests}

The tissue slabs reserved for histologic analysis were processed for permanentsection hematoxylin and eosin, according to the standard operating procedures of each site (site slides). The site also analyzed intraoperative frozen section or

Authors' version prior to publication. The published version is available at http://dx.doi.org/10.1016/j.amjsurg.2007.07.008, copyright @ 2007 by Excerpta Medica Inc. 
touch preparation slides taken from these same slabs according to their standard methods. Patient management was based solely on histologic analysis. Site personnel and patients were blinded to results from the BLN Assay.

\section{Central slides}

Additional histologic sections (central slides), adjacent to but separate from the sections prepared as Site Slides were taken, processed for permanent-section hematoxylin and eosin, and sent to a central pathology site for evaluation. Tissue was sectioned for central slides according to the study protocol; three 4- to 6- $\mu \mathrm{m}$ thick sections were collected at 3 levels, approximately $150 \mu \mathrm{m}(.15 \mathrm{~mm})$ apart. (Note: this would detect a .2-mm metastasis in a 1.5- $\mathrm{mm}$ slab in one third of cases or in a 3.0-mm slab in one sixth of cases, exceeding current College of American Pathologists' recommendations). When no metastasis was observable with hematoxylin and eosin staining, adjacent sections were also stained for immunohistochemical analysis, either on-site or by an outside laboratory (Albany Medical College, Department of Pathology, Albany, NY) and evaluated by the site pathologist or sent to the central laboratory for evaluation.

\section{Histologic evaluation}

Hematoxylin and eosin site slides and any site immunohistochemistry slides were examined by the site pathologist for evidence of metastases. All positive histologic findings (hematoxylin and eosin or immunohistochemical) on site slides were reviewed by central pathologists.

Each hematoxylin and eosin central slide was independently evaluated at the central pathology laboratory by 2 pathologists and a third pathologist in cases of disagreement. Only nodes with central review slide hematoxylin and eosin results were included in the study. A patient was considered positive if 2 independent pathologists evaluated the same histologic sections (either hematoxylin and eosin or immunohistochemistry slides) as containing metastasis $>.2 \mathrm{~mm}$. Central versus site slide results analysis permitted estimation of the amplitude of sampling error associated with conventional histologic evaluation (see Results). The overall histology result (OHR) was determined for each patient. When either the final central slides and/or final site slides (confirmed by central review) result was positive, the OHR for the node was designated positive. If either the site slide and/or any immunohistochemical results were not available, the central slide result alone was used as the OHR for the node.

\section{GeneSearch BLN Assay results}

All GeneSearch BLN Assay results were provided to Veridex for analysis (and blinded to site personnel). To provide a positive or negative assay sample result, the quantitative expression data were applied against specific mammaglobin and CK19 cutoff values based on data from the calibration (cutoff) study. The cutoff

Authors' version prior to publication. The published version is available at http://dx.doi.org/10.1016/j.amjsurg.2007.07.008, copyright @ 2007 by Excerpta Medica Inc. 
values were selected to correspond to histologically identified metastases $>.2$ $\mathrm{mm}$ in adjacent tissue slabs in $95 \%$ of cases. The cutoff values determined in the cutoff study ( $n=304$ patients) were then applied to the validation data set consisting of results from 416 independent patients. The assay result for a patient was considered positive if any node from the patient tested positive. If all nodes from a patient tested negative, then the assay result for the patient was considered negative. If the sample result from any node from a patient was invalid and all other node sample results were also invalid or negative, then the assay result for that patient was considered invalid.

\section{Analysis}

The primary endpoint was the overall agreement between the BLN Assay and the OHR for a given patient indexed to the size of metastatic deposits detected by histology and related to lobular versus other histology in the primary tumor. Secondary endpoints included (1) agreement of the BLN Assay with the OHR versus that of intraoperative frozen section and touch preparation and (2) a comparison of site slide versus central slide findings to provide a sampling error estimate for histological analysis. Eligible patients with invalid BLN Assay results were considered assay negative for performance calculations and were included in the analyses because, in clinical use, invalid results would not provide conclusive evidence of metastases and would provide the surgeon with no information on which to base clinical decisions. Invalid results can arise from inappropriate sampling (eg, all fatty tissue or no nodal tissue), operator error, or equipment malfunction. Bayesian statistical study design and analysis were performed and provided by Berry Consultants (Don Berry, Ph.D, and Scott Berry, Ph.D., Houston, TX). Statistical analyses, SAS programming, and validation were performed by Veridex.

\section{Results}

Experienced technicians performed the assay on 1 to 3 nodes in about 30 to 35 minutes compared with about 35 to 55 minutes for those with less practice. Assay performance was very similar in the validation and cutoff studies. Data are reported here for the validation study, except when the sample sizes are small; then the data are shown for both studies separately and combined. All analyses were performed on a "per-patient" basis. The intraoperative BLN Assay detected disease in $98 \%$ (95\% confidence interval, 93\%-100\%) of cases when histologically confirmed metastases $>2 \mathrm{~mm}$ were found in adjacent tissue slabs $(n=94)$. The assay was positive in $57 \%$ (95\% confidence interval, $35 \%-77 \%)$ of patients when micrometastatic disease .2 to $2 \mathrm{~mm}$ was detected in the adjacent slabs $(n=23)$. Overall, the assay reported metastasis $88 \%$ of the time when metastatic disease $\geq .2 \mathrm{~mm}$ was detected histologically in adjacent tissue slabs. When metastases $<.2 \mathrm{~mm}$ were found on histologic sampling of the adjacent tissue slabs (small clusters or isolated tumor cells), the assay was positive in 5 of 20 patients. The assay was positive in 12 of 275 (4\%) patients with no

Authors' version prior to publication. The published version is available at http://dx.doi.org/10.1016/j.amjsurg.2007.07.008, copyright @ 2007 by Excerpta Medica Inc. 
histologically detected cancer in adjacent tissue slabs. Table 1 shows the summary of BLN Assay results and OHR agreement.

Assay performance was similar across different stages of disease and across various tumor types (Table 2). The assay reported disease in approximately $80 \%$ of patients when lobular metastases (particularly difficult to identify by histology [4]) were present in adjacent tissue slabs. Table 3 shows the assay performance in lobular cancer patients in the validation study, cutoff study, and both studies combined when compared with OHR (permanent section histology).

Table 4 shows in the same patients the BLN Assay performance versus the performance of histologic intraoperative tests. Not all clinical sites used histologic intraoperative tests. All tests are compared with OHR. The assay detected about $10 \%$ more metastases than did frozen section (86 assay positive versus 77 frozen section positive of $90 \mathrm{OHR}$ positive) and nearly $30 \%$ more than did touch preparation ( 7 assay positive versus 5 touch prep positive of 11 OHR positive).

Early-stage disease and lobular cancers can be difficult cases in which to accurately detect metastases. Table 5 shows the performance of the BLN Assay versus that of frozen section in early-stage disease and in patients with lobular cancer. Data are shown for the validation study, cutoff study, and for both studies combined. The assay identifies metastatic disease in approximately $10 \%$ more patients with stage I disease and $25 \%$ more patients with lobular cancer than does frozen section (compared with total OHR positive).

Permanent section histologic evaluations are reported to miss at least $10 \%$ to $15 \%$ of metastases $>.2 \mathrm{~mm}$ because of practical limitations in sampling [7] and [12]. The same sampling errors necessarily contribute to the lack of perfect agreement between the BLN Assay and the OHR. This sampling error would be expected to be most apparent when metastases are small and infrequent, as with micrometastases. Figure 1 shows that the assay agreement with positive OHR found on adjacent $\sim 2$-mm node slabs is best when the metastases are larger and likely to be distributed across the assay and histology node pieces (the $P$ value of Cochran-Armitage test for trend is <.001).

There are fewer cases of BLN Assay-positive/histology-negative results when histologic sampling accuracy is increased. Thus, assay positivity is better matched by histology when more extensive sampling is used for the histologic evaluation (central and site slides combined) because this reduces the number of metastases being missed by histology (Table 6).

Sampling errors in histology testing are apparent when comparing histologic evaluations on the 2 sets of histologic slides: site slides versus central slides. These are nearby sections from the same $\sim 2$-mm node slabs, yet significant disagreements are seen where 1 set of slides contain metastatic tissue and the other set does not (Table 7, Table 8 and Table 9). The lack of perfect agreement

Authors' version prior to publication. The published version is available at http://dx.doi.org/10.1016/j.amjsurg.2007.07.008, copyright @ 2007 by Excerpta Medica Inc. 
is caused by the analysis of different section samples from the same lymph node because significant metastases can be missed in nearby tissue left uncut on the block [13] and [14]. If site slide findings are compared with central slide findings as the reference, the agreement of the 2 histologic evaluations approximates the agreement between the BLN Assay and OHR on different $\sim 2$-mm node slabs. These data confirm that the lack of perfect agreement between OHR and the BLN Assay is primarily caused by the evaluation of different parts of the node.

\section{Comments}

The currently recommended protocol for SLN processing (according to the College of American Pathologists, $5 \mu \mathrm{m}$ from 3 levels of each 2- to 3-mm fragment of the node [15]), guarantees evaluation of $<1 \%$ of the volume of the selected tissue [16]. Comprehensive histologic examination of a $1.5-\mathrm{cm}$ lymph node aimed at finding any metastasis $\geq .2 \mathrm{~mm}$ would require 75 sections, which is unobtainable in common practice. This limitation in the current standard of care makes it challenging to evaluate newer tests that are able to sample more tissue and are likely to be more sensitive than the "gold standard" reference test. The current study evaluated a new molecular test against a permanent section histologic protocol that was more thorough than is usually performed and used a central review of histologic slides to reduce evaluation errors. The study also evaluated histologic results on 2 sets of tissue sections taken from nearby regions of the same node. By comparing site slide findings to central slide findings, an estimate of sampling errors (differences caused by testing of different tissue from the same node) can be made. Because the BLN Assay produces a result by testing fresh homogenized tissue, the same tissue cannot be tested by both the assay and permanent section histology, which requires fixed tissue. This sampling difference will necessarily lead to disagreements between the assay and histology, especially when metastases are smaller and less widely distributed in the node.

The BLN Assay is a molecular test that can test $50 \%$ or more of the node in time to permit intraoperative evaluation. In a prospective study of 416 patients, with fresh nodal tissue tested by 11 clinical sites, the assay yielded efficient intraoperative detection of clinically important sentinel node metastasis, which will allow the surgeon and the patient to avoid a second operation for completion axillary dissection in $98 \%$ of patients if the policy is to return for metastases $>2$ $\mathrm{mm}$ or $88 \%$ if the policy is to return for any metastasis $>.2 \mathrm{~mm}$. Micrometastases (from .2 to $2.0 \mathrm{~mm}$ ) were less frequently detected $(57 \%)$ and assay-negative results in nodes found positive by histology were rare $(4 \%)$.

The disagreements seen between permanent section histology performed on adjacent-node slabs and the BLN Assay results were very similar to the disagreements seen between histology preformed on site slides versus central

Authors' version prior to publication. The published version is available at http://dx.doi.org/10.1016/j.amjsurg.2007.07.008, copyright @ 2007 by Excerpta Medica Inc. 
slides. These data indicate that when the assay and histology disagree, both tests are likely to be correct for the tissue portions each is evaluating. Discrepancies between evaluations on different node tissue (whether assay versus histology or histology versus histology) are greatest when metastases are small because they are poorly distributed in the node tissue. These findings support the need for tests that can efficiently evaluate more of the node for clinically significant metastases because breast cancer is found earlier and earlier and metastases will more likely be smaller.

As reported previously [17], in cases for which the BLN Assay result and the OHR were different, residual node homogenate or RNA extract from the assay testing was evaluated with other molecular markers for nodal metastases including B305D, B726, prolactin inducible protein, and prostate-derived Ets transcription factor [18], [19] and [20]. This testing was performed to confirm the BLN Assay results on the same tissue. These independent molecular test results confirmed as positive $76 \%$ of the BLN Assay-positive/OHR-negative nodes and confirmed as negative $100 \%$ of the BLN Assay-negative/OHR-positive nodes. These findings again suggest that when the BLN Assay and OHR are in disagreement, both are correct for the nodal portions each is evaluating.

Four percent of patients (17/416) had BLN Assay-positive results with no metastasis detected by conventional histology in adjacent tissue slabs. Could the assay produce real false-positive findings and lead to unnecessary axillary dissections? For reasons supported by our findings, we conclude that the BLNpositive/OHR-negative cases represent misses of metastatic disease by conventional histology. Histologic assessment of study sections taken immediately adjacent to standard site sections used for patient care shows the same study negative/standard-section positive rate. Study and standard site slides were all reviewed by the same pathologists. The assay is calibrated in in vitro studies to require approximately 2,000 cells to yield a positive result. External controls act as a further safety net against truly false-positive results. Recalibrating the assay cutoff to ignore or miss significant disease, at precisely the rate it is missed by conventional histology, would necessarily lead to lower sensitivity for the detection of clinically significant disease.

More detailed evaluation of the BLN Assay results indicates that the assay may be particularly helpful for difficult-to-detect early-stage breast cancer metastases or metastases from lobular cancer. Compared with current histologic frozen section intraoperative testing, the BLN Assay showed improved sensitivity ranging from approximately $10 \%$ to $30 \%$. Another advantage of the BLN Assay over frozen sectioning is that more tissue can be evaluated efficiently and there is no freezing artifact on the portions of node undergoing permanent section histology.

In summary, these data support the use of the BLN Assay as a properly calibrated intraoperative molecular test that can reduce the need for second

Authors' version prior to publication. The published version is available at http://dx.doi.org/10.1016/j.amjsurg.2007.07.008, copyright (C 2007 by Excerpta Medica Inc. 
surgeries to complete the axillary dissection on SLN-positive patients. In addition, the assay has value in augmenting permanent section histologic results to obtain better certainty of a correct node diagnosis by evaluating more of the tissue. The pathologist, surgeon, and patient can be more certain a negative node diagnosis is accurate when both the BLN Assay result on half of the node and standard histology on the other half are negative.

\section{References}

[1] A.J. Creager and K.R. Geisinger, Intraoperative evaluation of sentinel lymph nodes for breast carcinoma: current methodologies, Adv Anat Pathol 94 (2002), pp. 3016-3022.

[2] A.J. Creager, K.R. Geisinger and S.A. Shiver et al., Intraoperative evaluation of sentinel lymph nodes for metastatic breast carcinoma by imprint cytology, Mod Pathol 15 (2002), pp. 1140-1147.

[3] P.A. Treseler and P.S. Tauchi, Pathologic analysis of the sentinel lymph node, Surg Clin North Am 80 (2000), pp. 1695-1719.

[4] G. Viale, S. Bosari and G. Maxxarol et al., Intraoperative examination of axillary sentinel lymph nodes in breast carcinoma patients, Cancer 85 (1999), pp. 2433-2438.

[5] G. Cserni, Complete sectioning of axillary sentinel nodes in patients with breast cancer Analysis of two different step sectioning and immunohistochemistry protocols in 246 patients, J Clin Pathol 55 (2002), pp. 926-931.

[6] P.J. Van Diest, H. Torrenga and S. Meijer et al., Pathologic analysis of sentinel lymph nodes, Semin Surg Oncol 20 (2001), pp. 238-245.

[7] G. Cserni, What is a positive sentinel lymph node in a breast cancer patient? A practical approach, Breast 16 (2007), pp. 152-160.

[8] American Joint Committee on Cancer (AJCC), Cancer Staging Handbook (6th ed.), Springer-Verlag, New York (2002).

[9] Backus J, Green GA, Xu M, et al. Intraoperative molecular analysis of sentinel lymph nodes for the management of breast cancer surgery. Clin Cancer Res (in press). 
[10] P. Blumencranz, K.B. Deck and P.W. Whitworth et al., Abstracts and case studies from the College of American Pathologists 2006 Annual Meeting (CAP 2006), Arch Pathol Lab Med 130 (2006) 1362-1403..

[11] P. Querzoli, M. Pedriali and R. Rinaldi et al., Axillary lymph node nanometastases are prognostic factors for disease-free survival and metastatic relapse in breast cancer patients, Clin Cancer Res 12 (2006), pp. 6696-6701.

[12] M. Yared, L. Middleton and T. Smith et al., Recommendations for sentinel lymph node processing in breast cancer, Am J Surg Pathol 26 (2002), pp. 377382.

[13] G. Cserni, Metastases in axillary sentinel lymph nodes in breast cancer as detected by intensive histopathological workup, J Clin Pathol 52 (1999), pp. 922924.

[14] P.J. Van Diest, H. Torrenga and P.J. Borgstein et al., Reliability of intraoperative frozen section and imprint cytological investigation of sentinel lymph nodes in breast cancer, Histopathology 35 (1999), pp. 14-18.

[15] G.F. Schwartz, A.E. Giuliano, U. Veronesi and Consensus Conference Committee, Proceedings of the Consensus Conference on the Role of Sentinel Lymph Node Biopsy in Carcinoma of the Breast (2001) April 19-22, Philadelphia, PA.

[16] G. Farshid, M. Pradhan, J. Kollias and G. Grantley, Computer simulations of lymph node metastasis for optimizing the pathologic examination of sentinel lymph nodes in patients with breast carcinoma, Cancer 89 (2000), pp. 25272537.

[17] W. Cao, J. Backus and J. Vargo et al., Additional markers support results in a molecular breast sentinel lymph node diagnostic assay, Breast Cancer Res Treat 100 (suppl 1) (2006), pp. S1-S299.

[18] R.L. Houghton, D.C. Dillon and D.A. Molesh et al., Transcriptional complementarity in breast cancer: application to detection of circulating tumor cells, Mol Diagn 6 (2001), pp. 79-91.

[19] B.K. Zehentner and D. Carter, Mammaglobin: a candidate diagnostic marker for breast cancer, Clin Biochem 37 (2004), pp. 249-257.

[20] J. Backus, T. Laughlin and Y. Wang et al., Identification and characterization of optimal gene expression markers for detection of breast cancer metastasis, $J$ Mol Diagn 7 (2005), pp. 327-336. 


\section{TABLES \& FIGURES}

\section{Table 1.}

Summary of BLN Assay results and OHR agreement

\begin{tabular}{|l|l|l|l|l|c|}
\hline Assay-/OHR- & Assay+/OHR+ & Assay+/OHR- & Assay-/OHR+ & N & $\%$ Agreement \\
\hline $278(67 \%)$ & $106(25 \%)$ & $17(4 \%)$ & $15(4 \%)$ & 416 & 92.3 \\
\hline
\end{tabular}

For $\mathrm{OHR},+$ is metastases $>.2 \mathrm{~mm}$ and - is metastases $\leq .2$ or no detectable metastases.

\section{Table 2.}

Assay performance by stage and type of breast cancer

\begin{tabular}{|l|l|l|l|l|l|l|}
\hline $\begin{array}{l}\text { Tumor } \\
\text { stage/type }\end{array}$ & N & Assay-/OHR- & Assay+/OHR+ & Assay+/OHR- & Assay-/OHR+ & $\begin{array}{l}\% \\
\text { Agreement }\end{array}$ \\
\hline Stage I & 247 & $202(82 \%)$ & $29(12 \%)$ & $10(4 \%)$ & $6(2 \%)$ & 93.5 \\
\hline Stage II & 125 & $54(43 \%)$ & $55(44 \%)$ & $7(6 \%)$ & $9(7 \%)$ & 87.2 \\
\hline Stage III & 20 & $8(40 \%)$ & $12(60 \%)$ & $0(0 \%)$ & $0(0 \%)$ & 100 \\
\hline $\begin{array}{l}\text { Invasive } \\
\text { ductal }\end{array}$ & 335 & $223(67 \%)$ & $87(26 \%)$ & $14(4 \%)$ & $11(3 \%)$ & 92.5 \\
\hline $\begin{array}{l}\text { Invasive } \\
\text { lobular }\end{array}$ & 57 & $34(60 \%)$ & $16(28 \%)$ & $3(5 \%)$ & $4(7 \%)$ & 87.7 \\
\hline $\begin{array}{l}\text { Invasive } \\
\text { other }\end{array}$ & 23 & $20(87 \%)$ & $3(13 \%)$ & $0(0 \%)$ & $0(0 \%)$ & 100 \\
\hline
\end{tabular}

\section{Table 3.}

BLN assay results and OHR agreement in patients with lobular cancer

\begin{tabular}{|l|l|l|l|l|l|l|}
\hline Study & N & Assay-/OHR- & Assay+/OHR+ & Assay+/OHR- & Assay-/OHR+ & $\begin{array}{l}\% \\
\text { Agreement }\end{array}$ \\
\hline Validation & 57 & $34(60 \%)$ & $16(28 \%)$ & $3(5 \%)$ & $4(7 \%)$ & 87.7 \\
\hline Cutoff & 40 & $26(65 \%)$ & $10(25 \%)$ & $1(3 \%)$ & $3(8 \%)$ & 90.0 \\
\hline
\end{tabular}




\begin{tabular}{|l|l|l|l|l|l|l|}
\hline Study & N & Assay-/OHR- & Assay+/OHR+ & Assay+/OHR- & Assay-/OHR+ & $\begin{array}{l}\% \\
\text { Agreement }\end{array}$ \\
\hline Combined & 97 & $60(62 \%)$ & $26(27 \%)$ & $4(4 \%)$ & $7(7 \%)$ & 88.7 \\
\hline
\end{tabular}

\section{Table 4.}

Assay versus other intraoperative test performance

\begin{tabular}{|l|l|l|l|l|l|l|}
\hline $\mathbf{N}$ & Test method & Test-/OHR- & Test+/OHR+ & Test+/OHR- & Test-/OHR+ & $\begin{array}{l}\% \\
\text { Agreement }\end{array}$ \\
\hline 319 & $\begin{array}{l}\text { Frozen } \\
\text { Section }\end{array}$ & $224(70 \%)$ & $77(24 \%)$ & $5(2 \%)$ & $13(4 \%)$ & 94.4 \\
\hline & Assay & $216(68 \%)$ & $86(27 \%)$ & $13(4 \%)$ & $4(1 \%)$ & 94.7 \\
\hline 29 & Touch Prep & $18(62 \%)$ & $5(17 \%)$ & $0(0 \%)$ & $6(21 \%)$ & 79.3 \\
\hline & Assay & $18(62 \%)$ & $7(24 \%)$ & $0(0 \%)$ & $4(14 \%)$ & 86.2 \\
\hline
\end{tabular}




\section{Table 5.}

Assay and frozen section performance in stage I and lobular cancer patients

\begin{tabular}{|c|c|c|c|c|c|c|c|}
\hline Study & $\mathbf{N}$ & Test method & Test-/OHR- & Test+/OHR+ & Test+/OHR- & Test-/OHR+ & $\%$ Agreement \\
\hline \multicolumn{8}{|c|}{ Validation study } \\
\hline \multirow[t]{2}{*}{ Stage I } & 187 & Frozen & $158(84 \%)$ & $22(12 \%)$ & $3(2 \%)$ & $4(2 \%)$ & 96.3 \\
\hline & & Assay & $155(83 \%)$ & $25(13 \%)$ & $6(3 \%)$ & $1(1 \%)$ & 96.3 \\
\hline \multirow[t]{2}{*}{ Lobular } & 45 & Frozen & $30(67 \%)$ & $9(20 \%)$ & $1(2 \%)$ & $5(11 \%)$ & 86.6 \\
\hline & & Assay & 29 (64\%) & $14(31 \%)$ & $2(4 \%)$ & $0(0 \%)$ & 95.6 \\
\hline \multicolumn{8}{|c|}{ Cutoff study } \\
\hline \multirow[t]{2}{*}{ Stage I } & 100 & Frozen & $82(82 \%)$ & $11(11 \%)$ & $1(1 \%)$ & $6(6 \%)$ & 93.0 \\
\hline & & Assay & 77 (77\%) & $12(12 \%)$ & $6(6 \%)$ & $5(5 \%)$ & 89.0 \\
\hline \multirow[t]{2}{*}{ Lobular } & 24 & Frozen & $15(63 \%)$ & $6(25 \%)$ & $0(0 \%)$ & $3(12 \%)$ & 87.5 \\
\hline & & Assay & $15(63 \%)$ & $7(29 \%)$ & $0(0 \%)$ & $2(8 \%)$ & 91.7 \\
\hline \multicolumn{8}{|c|}{ Combined studies } \\
\hline \multirow[t]{2}{*}{ Stage I } & 287 & Frozen & $240(84 \%)$ & $33(11 \%)$ & $4(1 \%)$ & $10(4 \%)$ & 95.1 \\
\hline & & Assay & $232(81 \%)$ & $37(13 \%)$ & $12(4 \%)$ & $6(2 \%)$ & 93.7 \\
\hline \multirow[t]{2}{*}{ Lobular } & 69 & Frozen & $45(65 \%)$ & $15(22 \%)$ & $1(1 \%)$ & $8(12 \%)$ & 86.9 \\
\hline & & Assay & $44(64 \%)$ & $21(30 \%)$ & $2(3 \%)$ & $2(3 \%)$ & 94.2 \\
\hline
\end{tabular}

Authors' version prior to publication. The published version is available at http://dx.doi.org/10.1016/j.amjsurg.2007.07.008, copyright $\odot 2007$ by Excerpta Medica Inc. 


\section{Table 6.}

Assay performance by extent of histologic analysis

\begin{tabular}{|l|l|l|l|l|l|l|}
\hline $\begin{array}{l}\text { Reference } \\
\text { histology }\end{array}$ & N & BLN-/Hist- & BLN+/Hist+ & BLN+/Hist- & BLN-/Hist+ & $\begin{array}{l}\% \\
\text { Agreement }\end{array}$ \\
\hline $\begin{array}{l}\text { Central slides } \\
\text { only }\end{array}$ & 407 & $278(68 \%)$ & $91(22 \%)$ & $27(7 \%)$ & $11(3 \%)$ & 90.7 \\
\hline Site slides only & 407 & $275(68 \%)$ & $95(23 \%)$ & $23(6 \%)$ & $14(3 \%)$ & 90.9 \\
\hline $\begin{array}{l}\text { Central \& site } \\
\text { slides }\end{array}$ & 407 & $275(68 \%)$ & $101(25 \%)$ & $17(4 \%)$ & $14(3 \%)$ & 92.4 \\
\hline
\end{tabular}

\section{Table 7.}

Agreement between site slide results and central slide results

\begin{tabular}{|l|l|l|l|l|l|}
\hline Site slides & \multicolumn{5}{|c|}{ Central slides } \\
\hline & $>\mathbf{2} \mathbf{~ m m}$ &. $\mathbf{2 - 2} \mathbf{~ m m}$ & $<.2 \mathbf{m m}$ & None detected & Total \\
\hline$>2 \mathrm{~mm}$ & 79 & 3 & 0 & 4 & 86 \\
\hline $.2-2 \mathrm{~mm}$ & 5 & 9 & 0 & 9 & 23 \\
\hline$<0.2 \mathrm{~mm}$ & 0 & 2 & 0 & 4 & 6 \\
\hline None detected & 3 & 1 & 1 & 288 & 293 \\
\hline Total & 87 & 15 & 1 & 305 & 408 \\
\hline
\end{tabular}

\section{Table 8.}

Summary of site slides and central slides agreement

\begin{tabular}{|l|l|l|l|l|l|}
\hline Site-/central- & Site+/central+ & Site+/central- & Site-/central+ & N & $\%$ Agreement \\
\hline $293(72 \%)$ & $95(23 \%)$ & $13(3 \%)$ & $6(2 \%)$ & 408 & 95 \\
\hline
\end{tabular}

+ is metastases $>.2 \mathrm{~mm}$ and - is metastases $\leq .2$ or no detectable metastases. 


\section{Table 9.}

Site slides and central slides agreement for patients with detectable nodal tumor cells

\begin{tabular}{|l|l|l|l|l|l|}
\hline Site and/or central & $\mathbf{N}$ & Site+/central+ & Site+/central- & Site-/central+ & Total disagree \\
\hline$>2 \mathrm{~mm}$ & 94 & $87(93 \%)$ & 4 & 3 & $7(7 \%)$ \\
\hline $.2-2$ & 29 & $17(59 \%)$ & 9 & 3 & $12(41 \%)$ \\
\hline$<0.2$ & 7 & $2(29 \%)$ & 4 & 1 & $5(71 \%)$ \\
\hline
\end{tabular}

Fig. 1.

BLN assay positivity by the size of metastases in the adjacent tissue.

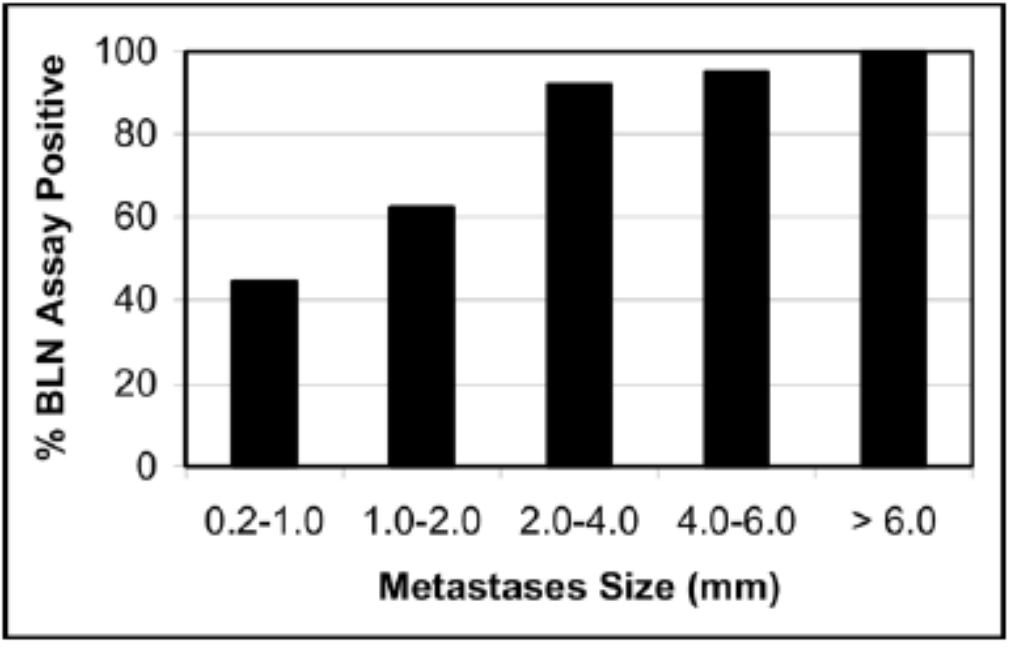

